\title{
Records, responsibility, and power: An overview of cataloging ethics
}

\author{
Jennifer M. Martin ${ }^{\mathrm{a} *}$ \\ ${ }^{a}$ Salisbury University Libraries, Salisbury University, Salisbury, MD, USA \\ *jmmartin@ salisbury.edu
}

The Version of Record of this manuscript has been published and is available in Cataloging \& Classification Quarterly (2021): https://doi.org/10.1080/01639374.2020.1871458.

Ethics are principles which provide a framework for making decisions that best reflect a set of values. Cataloging carries power, so ethical decision-making is crucial. Because cataloging requires decision-making in areas that differ from other library work, cataloging ethics are a distinct subset of library ethics. Cataloging ethics draw on the primary values of serving the needs of users and providing access to materials. Cataloging ethics are not new, but they have received increased attention since the 1970s. Major current issues in cataloging ethics include the creation of a code of ethics; ongoing debate on the appropriate role of neutrality in cataloging misleading materials and in subject heading lists and classification schemes; how and to what degree considerations of privacy and selfdetermination should shape authority work; and whether or not our current cataloging codes are sufficiently user-focused.

Keywords: cataloging ethics; radical cataloging; critical cataloging; cataloging values; neutrality; ethical issues

\section{Introduction}

In life, decisions necessitate ethics, and cataloging decisions are no exception to this. Decisions are abundant in cataloging. The most common decisions include things like choosing where to split the title and the subtitle, determining what notes should be included in the catalog record, and selecting what subject headings and classification to assign. Systemic decisions such as selecting a classification scheme, subject heading list, or bibliographic utility must also be made 
periodically. Every decision has an ethical impact, and those impacts matter because cataloging carries power.

Cataloging is often broken down into two parts: descriptive cataloging, which records basic descriptive information about the material such as title, author, publisher, and so on, and subject cataloging, which assigns subject headings and a classification number to the material. For both types of cataloging, cataloger's judgment (which is the considered application of professional experience to cataloging decisions) ${ }^{1}$ influences the decisions made when crafting a catalog record, and those decisions affect whether or not users can find information. Catalogers can, intentionally or not, hide or expose materials through the descriptive choices they make ${ }^{2}$ and the headings and classifications they do or do not assign. ${ }^{3}$ Wilson discusses how this gives catalogers power: knowledge is power, as the common adage goes, and so the ability to determine whether or not information (or knowledge) can be found is itself a form of power. ${ }^{4}$

In addition to influencing whether materials can be found, subject cataloging carries with it the power to name and organize knowledge, according to Olson, Adler, and others. ${ }^{5}$ Those who create and maintain controlled vocabularies and classification schemes decide what names will be given to concepts in the library and how the relationships between those named concepts will be organized. Catalogers individually or collectively decide what terms from which vocabularies and what classification numbers will be applied to name concepts in the records they create and use. Naming controls what can and cannot easily be talked about, grappled with, and faced. ${ }^{6}$ Organizing controls the relationships between concepts and the prioritization of identities and disciplines within the library. ${ }^{7}$ Olson and others argue that naming and organizing can cause harm by being complicit in the marginalization, exclusion, or erasure of people and ideas which fall outside of societal norms. ${ }^{8}$ As a different adage goes, with great power comes 
great responsibility, and so catalogers have a duty to be thoughtful and careful in how they wield their power.

To aid catalogers in that duty, this article introduces and provides an overview of the current state of cataloging ethics. After defining professional ethics and cataloging ethics, the article looks at the shared values and the ethical frameworks which together underpin cataloging ethics. A quick tour through history explores the ways cataloging ethics have evolved. The final section outlines current topics within cataloging ethics, including the in-development Cataloguing Code of Ethics, the role of neutrality in describing materials and in providing subject access, and the degree to which descriptive cataloging codes take into account the needs of users.

\section{What are professional ethics?}

As Beghtol explains, a profession is an occupation defined by a set of shared moral values. ${ }^{9}$ Professional ethics are a framework which guides the application of those values to professional decisions in order to have the actions of the professional and the outcomes of the profession align with the professional values. Defined professional ethics allow the professional to carry out their routine duties with confidence and help the professional to deal with edge cases where the right decision is not clear and where different values and needs may be in conflict.

\section{What are cataloging ethics?}

Catalogers adhere to the general ethics of the library profession as a whole, but due to the nature of their specialty, they also encounter concerns and decisions which are not common to the rest of the profession, which necessitates a more specific ethics to address those issues. ${ }^{10}$ Those specialized ethics are what is meant by the term "cataloging ethics." The Cataloging Ethics 
Steering Committee defines cataloging ethics as "Principles and values that provide an intentional decision-making framework for those who work in cataloging or metadata positions." ${ }^{11}$ At their core, cataloging ethics center the question of what the appropriate role of the cataloger is with regards to users seeking information, to creators of that information, and to those about whom information is created.

\section{Cataloging values}

Because ethics are built upon values, an understanding of cataloging ethics is predicated on an understanding of the professional values of the field of cataloging. The Statement of International Cataloguing Principles of the International Federation of Library Associations and Institutions (IFLA) declares that serving the needs of the user is the most important value underlying cataloging. ${ }^{12}$ Most other commonly cited values of cataloging are related to this core value of serving the needs of the user. These other values include making materials accessible, providing accurate records, and neutrality. The importance of making materials accessible generally rests on the assumption that a core need of the user is to access information. ${ }^{13}$ Accurate records make it easier to find information. ${ }^{14}$ Neutrality is often posited as the best way to allow users to find materials that meet their needs without the cataloger's biases or opinions interfering $;{ }^{15}$ however, neutrality as a value has also been heavily criticized for not leading to unbiased representation but instead reproducing the norms and harms of the dominant culture. ${ }^{16}$ Reduction of harm (or doing the least harm possible) is an additional value which is sometimes discussed ${ }^{17}$ and sometimes implicit, ${ }^{18}$ but which is also quite common in cataloging ethics literature. 


\section{Ethical frameworks}

Values alone do not create professional ethics; an ethical framework is also required. Because professional ethics are intended to give the professional a basis for judging the best course of action to uphold their professional values, it is necessary to consider how "best" should be determined. ${ }^{19}$ Ethical frameworks are the articulation of this consideration. Many different ethical frameworks have been proposed over the years by ethical philosophers. Some of the most common, both in general and in library science, are utilitarianism, Kantian deontology, egoism, natural law, justice ethics, the feminist ethic of care, and pragmatic ethics. ${ }^{20}$ These approaches are very briefly outlined below. In addition, Fox and Reece note, many considerations of cataloging ethics have relied on an assumed general sense of right and wrong or "common sense" rather than any given philosophical ethical framework. ${ }^{21}$

Utilitarianism holds that the best actions are those that create the most good or the most happiness for the most people. This approach focuses on outcomes. Two major drawbacks are that it can allow even large amounts of individual harm if that harm advances the common good and that it can allow unethical means to ethical ends. ${ }^{22}$

Kantian deontology holds that ethical actions are predicated on choosing to do one's duty (the "categorical imperative"); one's duty is predicated on principles that universally treat all people with respect. This approach focuses on methods. Two major drawbacks are that it does not allow exceptions to ethical rules and that it views intent as the only prerequisite for ethical choices, with no consideration of whether the actual impact is good. ${ }^{23}$

Egoism holds that ethical actions are those which bring the individual the greatest wellbeing and self-satisfaction (often expressed as "the most happiness"). A major drawback is that it can promote individual good at the expense of others or of the common good. ${ }^{24}$ 
Natural law holds that ethical actions are those which comport with self-evident universal principles of what is right. Two major drawbacks are that it requires making normative claims of ethics with no allowance for cultural differences and that it usually assumes the existence of God, particularly the Catholic conception of God. ${ }^{25}$

Rawlsian justice ethics holds that ethical action is predicated on following rational, universalized principles which are designed to ignore bias and treat everyone equally. Two major drawbacks are that this approach assumes that everyone is starting from an equal point and that it expects people to choose to and to be able to detach from their own biases. ${ }^{26}$

The feminist ethic of care holds that ethical action is that which maintains or repairs relationship and thus is always contextual. Two major drawbacks are that this approach resists the creation of standardized or common understandings of ethical action—of any sort of code of ethics - because of its emphasis on context and that it can endorse even extreme partiality. ${ }^{27}$

Pragmatic ethics hold that ethical actions are those which are efficient and are built upon observable measures, which measures must then be checked and the results used to further refine practice. A major drawback is that this approach requires a serious time commitment to implement. ${ }^{28}$

In general, professional ethics and ethical arguments rarely apply a philosophical ethical framework in its pure form, instead drawing from the strengths of different approaches. The framework chosen heavily impacts what is considered ethical, which is why, as Fox and Reece argue, it is important to define the ethical framework being used before moving onto considerations of ethical action. ${ }^{29}$ Fox and Reece propose a framework specifically for cataloging that combines a number of approaches in a way that emphasizes their strengths and 
mitigates their weaknesses, ${ }^{30}$ but no unified, widely agreed upon ethical framework currently exists for cataloging. ${ }^{31}$

\section{What is the history of cataloging ethics?}

As with most human constructs, ethics are not static. Our understanding of desired outcomes and of types of harm and how to mitigate that harm shifts, and so ethics necessarily shifts with it.

\section{Early librarianship through the 1960s}

Ethics in librarianship and in cataloging is not a new concept. Guthrie notes that as far back as the Middle Ages, librarians understood a duty to catalog their collections, even when collections only held a few dozen to a few thousand books. Various forms of classification were created and used with the goal of providing organized access to knowledge. However, Guthrie's research does not indicate that the needs of the user were considered important, much less paramount. ${ }^{32}$

Prioritizing the needs of the user had emerged as a guiding principle by the mid-1800s. In 1841, Panizzi published his "Rules for the Compilation of the Catalogue" for the British Museum, laying out 91 rules for how records should be created. ${ }^{33}$ When the resulting cataloging work was criticized for being too slow—-to the point that a Parliamentary commission was created to look into the matter-Panizzi's defense was that users should be able to find the specific edition they wanted, and that the degree of detail in his code was necessary for that. His opponents countered that users did not generally need that degree of detail, and that having some sort of record sooner rather than later was more important to the user. The commission ruled in favor of Panizzi, ${ }^{34}$ but this debate about serving user needs best through speed or through detail is still ongoing. 
Cutter's Rules for a Printed Dictionary Catalogue, first published in $1876,{ }^{35}$ became one of the foundational texts for modern cataloging standards. The fourth edition of Cutter's Rules, published in 1904, introduced the oft-quoted principle that "the convenience of the public is always to be set before the ease of the cataloger, ${ }^{, 36}$ an explicit statement of the value of meeting the needs of the user.

By the 1930s, the inadequacy of existing subject and classification treatment of minorities, particularly Black people, was acknowledged in practice. Dorothy Porter, among others, began the continuing tradition of creating supplemental or alternate subject heading lists and classification schemes to address the failures of the major standards. ${ }^{37}$ However, cataloging ethics were not yet a significant topic of professional discourse. ${ }^{38}$

\section{0s to present}

In 1971, Sanford Berman's publication of Prejudices and Antipathies: A Tract on the LC Subject Heads Concerning People, which outlined outdated and offensive subject headings and recommended remedies, ${ }^{39}$ started a shift in the conversation around cataloging ethics. Others joined his call to urge or demand improvement to the mainstream standards, creating a movement which is often referred to as "radical cataloging." This work of identifying, exposing, and correcting biased, outdated, pejorative, or inaccurate headings continues today. ${ }^{40}$

Starting in the 1990s, greater focus began to be paid to other ethical issues in cataloging, a focus which has continued to grow. ${ }^{41}$ With shrinking library budgets, the tension between detail and speed came roaring back into focus and discussion. Ethical considerations drawing on fields outside of the library, such as feminism, queer theory, and post-colonialism, became common. Over this time, it has become more and more accepted that inclusivity is a necessary 
value for cataloging because a library and its catalog cannot effectively serve the needs of users who are being marginalized or discriminated against within the library. ${ }^{42}$

In 2009, IFLA released a Statement of International Cataloguing Principles, outlining not just the objectives and rules necessary for internationally cooperative cataloging but also a list of general principles which should underlie cataloging codes. In 2018, the international Cataloging Ethics Steering Committee was formed with the goal of creating a cataloging-specific code of ethics; this work is ongoing as of this writing.

Even though cataloging as a profession has, for the most part, reached common agreement on the underlying values for cataloging, many specific issues are still being debated with little to no action or resolution having been reached.

\section{What are current issues within cataloging ethics?}

\section{Cataloging code of ethics}

Bair argued in 2006 and other catalogers in discussions have since echoed that cataloging involves ethical issues and conundrums which do not affect librarianship as a whole, which therefore leaves the general codes of ethics insufficient to meet the professional ethical needs of catalogers. ${ }^{43}$ And as the recent proliferation of debate has shown, there are a multitude of ethical issues in cataloging. Thus, in 2017, the Cataloging and Metadata Management Section (CaMMS) of the Association for Library Collections \& Technical Services (ALCTS) of the American Library Association (ALA) started the conversation around potentially creating a code of ethics for catalogers, hosting a discussion session at the 2017 ALA Annual Conference ${ }^{44}$ and an ALCTS e-Forum discussion later that year. ${ }^{45}$ Enough support was present that the decision was made to move forward with creating a cataloging code of ethics. Canadian and British catalogers 
expressed interest in joining the effort. This led to the creation of the Cataloging Ethics Steering Committee, composed of representatives from CaMMS, from the Metadata and Discovery Group (MDG), formerly the Cataloguing and Indexing Group (CIG), of the Chartered Institute of Library and Information Professionals (CILIP) in the United Kingdom, and from the Cataloguing and Metadata Standards Committee (CMSC) of the Canadian Federation of Library Associations (CFLA-FCAB). The Committee created and led working groups to determine what should be in the code of ethics and then drafted a proposed code. At time of writing, the draft code of ethics was available for public comment; the Cataloging Ethics Steering Committee website contains up-to-date information on the process and a link to the draft. ${ }^{46}$

\section{Speed versus detail}

As mentioned previously, the ethical tension between the speed of cataloging and the detail of cataloging is long-standing. The proponents of each viewpoint argue for meeting the needs of the user, yet the two are mutually exclusive: an individual cataloger can either take the time to add detailed information to the cataloging record or they can work more quickly by omitting details. This tension has been exacerbated in recent decades by shrinking library budgets, which has generally led to attrition in the number of cataloging positions at any given library, putting additional pressure on catalogers to increase their speed or face (larger) backlogs of uncataloged materials. Those arguing for detail hold that users need to be able to find precise editions in the catalog and that users are not well served by scanty records, unless they are doing known item searches. ${ }^{47}$ This view underlies most modern cataloging codes, and dominates the cataloging discourse. Those arguing for speed argue that since users have no access to materials if said materials are uncataloged, users are best served by having the cataloging done as quickly as

possible, even if that results in less than excellent records. ${ }^{48}$ This debate shows no signs of being 
resolved any time soon.

As an example, Banush and LeBlanc discuss how their library chose to address this dilemma in practice. ${ }^{49}$ Due to local policies which required detailed cataloging for each item received and a shrinking cataloging department, they had a growing backlog of over 100,000 items. In evaluating the situation, the cataloging department decided that backlogs did not serve the needs of the user and thus needed to be eliminated. This was accomplished by making use of unchanged copy cataloging, by relying on automatic record matching, and by reducing the amount of detail included in their original cataloging. These changes allowed them to achieve their goals of eliminating the existing backlog and of cataloging all new materials upon receipt.

\section{Neutrality}

Another long-standing, ongoing debate is over the role of neutrality in cataloging. This is where the bulk of recent discussions of cataloging ethics fall. There are two main questions involved: whether or not neutrality is possible and whether or not neutrality as a goal is desirable. This debate also ranges over three aspects of cataloging: cataloging choices, particularly when dealing with ambiguous or misleading materials; authorized terms, including subject headings and name authorities; and classification.

The following paragraphs summarize the arguments around the possibility and desirability of neutrality. These arguments are not always made explicit in discussions of cataloging neutrality, yet they are the foundation of the debate, and understanding them helps clarify the common positions taken in the discussions.

A complication of the debate is that not everyone defines neutrality in the same way. For some, such as Berman, Wenzler, and McMenemy, neutrality means committing to including all viewpoints, even those which are marginalized or unpopular. ${ }^{50}$ For others, such as Jensen and 
Adler, neutrality means not taking sides, that is, adopting a stance intended to be apolitical. ${ }^{51}$ The former definition is most common among those who support neutrality, while the latter definition is more common among those who challenge neutrality.

Wenzler and Bair discuss neutrality as the practice of catalogers setting aside their biases in order to provide objective access to knowledge ${ }^{52}$ Berman adds the consideration that cataloging systems should reflect universal knowledge without bias. ${ }^{53}$ From this, it can be seen that a belief in the possibility of neutrality requires believing that catalogers can separate themselves from their biases in their professional life and that it is possible to create a system that accurately and completely summarizes and categorizes all human knowledge. Generally, those who espouse neutrality place importance on equally presenting all sides. ${ }^{54}$ As reflected in Berman and Wenzler, most who hold this view acknowledge that bias currently exists in cataloging systems and argue that bias should be addressed by a greater commitment to neutrality. ${ }^{55}$

Not everyone agrees that bias can be addressed through neutrality. As discussed in Macdonald and Vaughan, some librarians hold that dismantling bias within existing systems is not neutral but is ethically important; social justice is prioritized over any conception of neutrality. ${ }^{56}$ Those who hold this view may or may not believe neutrality is possible.

Jensen, Martínez Ávila and Guimarães, Drabinski, and Vaughan argue that neutrality is not possible. ${ }^{57}$ Each person is inevitably biased, the argument goes, due to the bounds of their lived reality; individual neutrality is therefore not possible. ${ }^{58}$ Additionally, Drabinski and Martínez Ávila and Guimarães assert that universal truth does not exist; truth is always constructed by the society it exists in and therefore is always contingent upon the context of that society. ${ }^{59}$ Social or systemic neutrality is thus impossible because no meaningful standard exists 
against which to measure "neutral." According to Adler, Vaughan, and Martínez Ávila and Guimarães, all systems inherently reflect the biases of the culture that created them, ${ }^{60}$ although Vaughan notes that involving more people may reduce bias due to the input of multiple perspectives. $^{61}$

Those who reject neutrality hold that "neutrality" is not actually neutral. Olson, Jenson, Adler, and others argue that the "neutral" stance is a choice to not challenge the biases, norms, and power distribution that currently exists, and thus is effectively a choice to support the status quo instead of any alternative. Therefore, what is termed neutrality is not only not neutral, but actually harmful because it perpetuates and reinforces existing power imbalances. ${ }^{62}$ Those who hold that neutrality is not possible wrestle with a vital question: If our cataloging systems are inherently and inescapably biased, how then do we organize and describe information ethically?

\section{Misleading materials ${ }^{63}$}

The debate over neutrality is most prominent in cataloging practice when considering how to catalog misleading materials, and much of this debate takes place informally in discussions among catalogers, such as on email lists, rather than in the literature. "Misleading materials" is used here to mean materials whose surface presentation does not accurately or fully reflect their contents, whether that is because they are, for example, fiction presented as non-fiction or are biased and hate-filled materials.

Those in favor of neutrality argue that catalogers should only record as much information as is available on the item itself. Going beyond that is viewed as recording value judgments about the material, which is not neutral. Proponents view this form of neutrality as the best way to provide information to users without inserting the cataloger's own biases, which may not agree with those of the users, into the process. Cataloging materials "as they present themselves" 
is currently the dominant ethical position and is supported by library codes of ethics which include or imply neutrality as a core ethical principle for librarians ${ }^{64}$ as well as by Library of Congress policy for cataloging. ${ }^{65}$

The counter position is that because neutrality is not actually neutral, catalogers should instead use their judgment to note in the cataloging records the prejudices, biases, or misleading nature of materials. Some proponents argue that describing materials solely as they present themselves is inaccurate and perpetuates misinformation and that catalogers should therefore indicate that the materials contain objectionable or inaccurate content as a service to the user. ${ }^{66}$ The counterargument to that argument points out that different groups have very different views on what is and is not problematic, so such an approach raises the question of whose views get enshrined as "correct."

A nearly endless variety of misleading works exist; the following examples illustrate some common themes. In some cases, the reader is expected to be aware that the surface presentation is not the full truth, such as with Millie's Book, which lists Millie the dog as author, ${ }^{67}$ and the books in the Geronimo Stilton series, which list the eponymous mouse as author. ${ }^{68}$ In other cases, though, the reader is unlikely to be aware that aspects of the work are untrue or misleading unless the reader has outside information, and these works may be intentionally deceptive; examples of this category include We Indians: The Passing of a Great Race, which purports to be the recollections of Big Chief White Horse Eagle but which was likely not written by the chief, ${ }^{69}$ and Arming America: The Origins of a National Gun Culture by Michael A. Bellesiles, which has been deemed by other scholars to be severely misleading. ${ }^{70} \mathrm{~A}$ third category includes works whose standard bibliographic description (in particular, the title, summary or abstract, and table of contents) does not indicate the presence of racism, 
homophobia, etc., within those works, such as with the racism underlying the theories within Anthropology: An Introduction to the Study of Man and Civilization by Edward B. Tylor. ${ }^{71}$ This third category is discussed as misleading because the readers cannot tell from a standard catalog record that the works contain content which is currently commonly deemed offensive.

\section{Standards for subject access}

Another area where the debate about neutrality plays out is in the standards for subject access. It has been widely acknowledged that controlled vocabularies for subjects (particularly national subject heading lists, such as the Library of Congress Subject Headings) and classification schemes (such as the Library of Congress Classification and the Dewey Decimal Classification) cannot be neutral. Critics argue that these systems reflect and reinforce cultural norms which are harmful to non-dominant peoples and cultures, with LGBTQ+ people, racial and ethnic minorities, religious minorities, and people from non-Western countries most frequently discussed.

Subject Heading Lists. Critics argue that subject heading lists can be problematic because pejorative or imposed terms or names are used for marginalized or oppressed groups; ${ }^{72}$ more specific headings are only created for groups which don't fit the cultural idea of "normal" for the topic (a practice often called "exceptionalism"); ${ }^{73}$ or concepts central to those with marginalized or oppressed identities are inaccurately reflected or not reflected at all in the subject heading lists, thereby writing those concepts out of the easily searchable "canon" of knowledge. 74 Because of these issues, the argument goes, the headings fail to provide access to the materials they are applied to by failing to reflect how people search for information on those topics. ${ }^{75}$ Several critics assert that the presence of such headings also makes people in marginalized 
groups feel unwelcome or unsafe in the library, reducing their willingness to interact with the library and thereby restricting their access to information. ${ }^{76}$

The Library of Congress Subject Headings (LCSH) are updated based on the concept of "literary warrant;" that is, the presence of a concept or topic in published literature is both sufficient and necessary for a corresponding subject heading to be added to the list. Olson points out that this use of literary warrant causes LCSH to reflect the societal biases present in what does and does not get published. ${ }^{77}$ Additionally, Adler notes that while using literary warrant in theory allows LCSH to objectively reflect published literature, in practice terms present in the literature may still be rejected, with terms relating to marginalized groups being more likely to be rejected. ${ }^{78}$

Calls to correct the established subject headings, to add new headings, and to allow people in marginalized groups greater input into and control over how they are reflected in the catalog are common. ${ }^{79}$ A number of group-specific subject heading lists have been created by or in consultation with the respective affected group in order to provide an alternative to the problematic common headings lists. ${ }^{80}$

A well-publicized example about the neutrality of subject headings is the attempt to change the heading "Illegal aliens" in LCSH. ${ }^{81}$ Students at Dartmouth College spearheaded a proposal and campaign to have the Library of Congress change the heading, arguing the term was pejorative. After several years and much advocacy, the Library of Congress announced that it was going to replace "Illegal aliens" with the headings "Noncitizens" and "Unauthorized immigration." However, the U.S. Congress proposed legislation which would forbid the Library of Congress from changing the heading; ultimately, the bill was amended to only direct the Library of Congress to publicize their methods for changing subject headings, but it still 
succeeded in its original intent: the Library of Congress has to date not revised "Illegal aliens." This is the first and only known time that Congress has intervened in Library of Congress changes to subject headings. ${ }^{83}$ Not all librarians agreed with the terms that the Library of Congress proposed instead of "Illegal aliens;" many argued that "Undocumented immigrants," even if less legally precise, was the more common term and should therefore be chosen because that is what people were most likely to search on.$^{84}$ In the wake of the Library of Congress' inaction, a number of libraries have made local changes to remove the term from their catalog or to at least provide alternative terms; of these, most have chosen to use "Undocumented immigrants" rather than the Library of Congress' proposed terms. ${ }^{85}$

Fina points out another example of this sort of problem: in 1993, the subject heading "Socially handicapped" in LCSH was used to indicate materials on services for people who do not speak the dominant language of where they live, such as Spanish-speakers in the United States. ${ }^{86}$ Fina notes that such people do not think of themselves in those terms, so such materials are essentially hidden from them because they would never think to search under that subject heading. ${ }^{87}$ The heading has since been revised to "People with social disabilities," which reflects the broader narrative shift from "handicapped" to "people with disabilities" but does not solve the problem of being a subject term that would not be thought of or identified with by those it describes.

Classification schemes. Classification schemes organize knowledge in order to make finding related materials easier, usually arranging knowledge by subject, topic, or discipline. Classification schemes can attempt to organize and represent all knowledge found in all works collected by libraries, like Library of Congress Classification (LCC) and Dewey Decimal Classification (DDC) do, or they can focus on a specific field or area of knowledge. In either 
case, those who create and maintain classification schemes must decide which concepts should be grouped together and which other concepts must therefore be split apart. ${ }^{88}$ The creators and maintainers must also decide what conditions or justifications must be met in order to add new concepts to the classification scheme. Critics argue that these decisions are not value-neutral because they determine whose viewpoints and ways of knowing are reflected in the schemes. ${ }^{89}$

LCC and DDC were created in the late 1800s based on existing library collections in the United States and have since used the concept of literary warrant to govern their updates. ${ }^{90}$ Because of that background, critics argue, those schemes reflect a white, male-dominated, colonial, US-centric, Christian, etc., perspective. ${ }^{91}$ As a result, the schemes often fail to organize materials in ways which are easily accessible to people from non-dominant cultures and may, as Adler argues, organize materials in ways which are outright harmful to minority cultures.$^{92}$ For example, consider the way that DDC handles religion: Christianity occupies $86 \%$ of the top-level space dedicated to specific religions, whereas all the other religions of the world are squished

into the remaining $14 \%$ of the top-level space. ${ }^{93}$ As another example, classifications for materials on African Americans and LGBTQ+ people in LCC are scattered throughout the scheme; Howard and Knowlton argue that this makes it much harder for researchers to find the full breadth of material available on these topics in a given library. ${ }^{94}$ As with subject headings, alternate or expanded classification systems have been created in response to the major systems' shortcomings. ${ }^{95}$ These alternate systems often focus on specific cultures, topics, or user groups rather than seeking to categorize all knowledge for all people.

\section{Changing terms}

An additional line of argument made around the issues of classification, subject headings, and neutrality uses queer theory to argue that trying to create a system that comprehensively captures 
all human knowledge is, by nature, impossible. In queer theory, each person is always navigating the tension between their reality (which is beyond and outside of language) and the words used to capture that reality; as a result, all knowledge is contextual and contingent, unable to ever be fully and finally organized and expressed. ${ }^{96}$ Drabinski argues that because of this contingency, the endless race to fix subject headings and classifications is a fool's errand which actually only helps paper over the bias of the structures and that users would therefore be better served by librarians leaving the issues in place and instead focusing on teaching users to critically engage with the catalog as a flawed text. ${ }^{97}$ On the other side, Vaughan argues that because language and knowledge are eternally shifting, catalogers have an ethical duty to always be alert to changes in meaning and use and to revise the subject headings and classification schemes to reflect those changes. ${ }^{98}$

\section{Authorized access points for names}

Authorized access points for names have received scrutiny and criticisms related to issues of self-determination and privacy. Self-determination is the ability to decide one's own identity and to control how that identity is presented to the world; a fundamental premise of this form of criticism is that treating people and groups with respect necessitates calling them by the names they use for themselves. ${ }^{99}$ Privacy is the ability to control what information about oneself is revealed, when, and to whom.

An example of this sort of critique is the debate around recording gender in authority records. Authority records establish an authorized form of a name to be used in catalog records to uniquely identify a person, group, or entity. Generally, authority records include any alternate names of the person, group, or entity; any alternate forms of the authorized name; and identifying information about the person, group, or entity being named. Resource Description 
and Access (RDA), the descriptive cataloging code implemented in 2013, added a number of new characteristics which could be recorded in authority records for people; one of those characteristics was gender, with acceptable terms listed as "male," "female," and "not known." The Library of Congress instructed members of the Program for Cooperative Cataloging (PCC) to record gender for all individual creators, even if the recorded gender was an assumption on the part of the cataloger. ${ }^{101}$ Billey, Drabinski, and Roberto wrote a critique of this rule and practice, arguing that gender should not be recorded because creators do not necessarily want their gender included and because identifying and recording gender is nowhere near as simple as RDA and the Library of Congress made it seem. ${ }^{102}$ The authors acknowledge that not recording gender would make searching based on the creator's gender identity more difficult, but felt that that was an acceptable trade-off to protect the creators, for much the same reason that ethnicity was not included as a recordable characteristic. ${ }^{103}$ This critique in turn sparked the creation of a Program for Cooperative Cataloging ad hoc committee, which created a report instructing catalogers to record gender only if it was explicitly and publicly disclosed by the creator; ${ }^{104}$ however, the Program for Cooperative Cataloging never made the recommended policy changes. The way gender is recorded and reflected in authority records is still a topic of debate. ${ }^{105}$

Another example of self-determination critique is the argument that creators and groups should determine what name they are referred to by in their authorized heading, especially for colonized and oppressed peoples. ${ }^{106}$ Name headings for people, places, and groups from colonized cultures often do not reflect the names that those people use for or within their own cultures; instead, the authorized name is the name that was imposed by Westerners. ${ }^{107}$ Names from other cultural linguistic traditions, when brought into the Library of Congress Name Authority File, often have English name norms imposed upon them, such as inserting a comma 
between the surname and personal name of Asian creators whose names are not inverted from their culturally correct order. ${ }^{108}$ Some have created specialized name authority files in collaboration with the people and groups named in order to provide alternatives to inadequate or offensive national name authority files. ${ }^{109}$

\section{Descriptive cataloging codes and the needs of the user}

Another criticism which is not new but which has come much more strongly to the forefront in the past decade or so is that descriptive cataloging codes themselves do not sufficiently take into account the actual needs of users. This criticism was made in the late $1960 \mathrm{~s},{ }^{110}$ reappeared in the early $1990 \mathrm{~s},{ }^{11}$ and then resurfaced again in the late 2000s. ${ }^{112}$ RDA in particular has sparked debate among catalogers as to whether it is sufficiently user-oriented. ${ }^{113}$ Gorman, ${ }^{114}$ Hufford, ${ }^{115}$ and Hoffman ${ }^{116}$ argue that descriptive cataloging standards have been developed without a fundamental understanding of users and what they need, assuming users' needs instead of studying how users actually search for information. In other words, user studies have not been done as part of the creation of the codes themselves, and the studies which have been performed are focused on improving existing systems (mostly catalogs); this puts catalogers in the frustrating bind of not knowing if the codes they follow accurately guide them to best serve the needs of their users. ${ }^{117}$ Those making these criticisms argue that users' actual behavior should be studied apart from existing systems and then cataloging rules should be created that meet those proven needs. ${ }^{118}$

\section{Other criticisms}

Other less frequent but still significant ethical criticisms include the costs of the tools which provide access to primary cataloging standards, such as RDA Toolkit, ClassWeb, and 
WebDewey, and how those costs affect equal access to said shared standards $;{ }^{119}$ considerations of the working conditions of catalogers, including questions of who is seen as professional, how much professionals and non-professional staff are being paid, and how much training is provided for those doing cataloging; ${ }^{120}$ to what purpose certain details are being included in the catalog records $;{ }^{121}$ and the accessibility of catalogs and discovery layers for people with disabilities. ${ }^{122}$ Accessibility of the catalog has been discussed far more as a public services question than as a question of cataloging ethics, despite its direct relationship to the catalog and the work of catalogers.

\section{Conclusion}

Ethical cataloging matters because catalogers control access to the information in library materials. Cataloging ethics guide the creation of cataloging practice and the decisions of catalogers as they do their work. Core cataloging values are to serve the needs of the user and to provide access to information. Cataloging ethics are by no means a new field, with evidence of some form of ethics as far back as the Middle Ages. In recent years, ethical debate has focused on issues of neutrality, inclusivity, self-determination, and privacy. An understanding of ethics is vital for all catalogers so that they can successfully navigate the ethical challenges they face in their career and contribute their voices to the shaping of cataloging ethics. All catalogers are encouraged to consider how they might apply their ethical principles to their practical cataloging work and to act on their conclusions. In this way, they can help build an ever more ethical cataloging practice.

Acknowledgements: The author would like to thank Violet Fox, Nicole Kulp, and Audrey Schadt for their feedback on an early draft of this article. The author would also like to thank the anonymous peer reviewers and Gretchen Hoffman and Karen Snow for their feedback on a later draft. 


\section{Notes}

${ }^{1}$ Cataloger's judgment most frequently is applied in situations where cataloging rules are flexible or imprecise. The concept also includes a recognition that catalogers can make different decisions from each other without any of them necessarily being wrong. See Junli Diao, "Conceptualization of Catalogers' Judgment through Content Analysis: A Preliminary Investigation," Cataloging \& Classification Quarterly 56, no. 4 (2018): 298-316.

${ }^{2}$ David W. Bade, The Creation and Persistence of Misinformation in Shared Library Catalogs: Language and Subject Knowledge in a Technological Era (Champaign: Publications Office, Graduate School of Library and Information Science, University of Illinois at Urbana-Champaign, 2002).

${ }^{3}$ Sheila Bair, "Toward a Code of Ethics for Cataloging," University Libraries Faculty \& Staff Publications 11 (2005): 10-12, https://scholarworks.wmich.edu/library_pubs/11 (accessed June 25, 2020); Melissa Adler, Cruising the Library: Perversities in the Organization of Knowledge (New York: Fordham University Press, 2017), 12; Marielena Fina, “The Role of Subject Headings in Access to Information," Cataloging \& Classification Quarterly 17, no. 1-2 (1993): 267-74. doi:10.1300/J104v17n01_19; Melodie J. Fox and Austin Reece, "Which Ethics? Whose Morality?: An Analysis of Ethical Standards for Information Organization," Knowledge Organization 39, no. 5 (2012): 377; Hope A. Olson, "The Power to Name: Representation in Library Catalogs," Signs: Journal of Women in Culture and Society 26, no. 3 (2001): 639-68.

${ }^{4}$ Patrick Wilson, Two Kinds of Power: An Essay on Bibliographic Control, (Berkeley, CA: University of California Press, 1968), 4. See also Adler, Cruising the Library, 9; Olson, "Power to Name."

${ }^{5}$ Olson, "Power to Name"; Melissa Adler and Joseph T. Tennis, "Toward a Taxonomy of Harm in Knowledge Organization Systems," Knowledge Organization 40, no. 4 (2013): 267-68; Adler, Cruising the Library, 9; Bair, "Toward a Code," 5.

${ }^{6}$ Adler and Tennis, "Taxonomy of Harm," 268; Carol Anderson, "White Rage: The Unspoken Truth of Our Nation's Divide,” lecture, John F. Morgan Sr. Distinguished Faculty Lecture from Emory University, Atlanta, GA, April 9, 2018, accessed July 29, 2020, https://youtu.be/YBYUET24K1c, 4:10-4:20; Hope A. Olson, The Power to Name: Locating the Limits of Subject Representation in Libraries (Dordrecht: Springer, 2002), 4-6; Crystal Vaughan, “The Language of Cataloguing: Deconstructing and Decolonizing Systems of Organization in Libraries," Dalhousie Journal of Interdisciplinary Management 14: 11.

${ }^{7}$ Olson, "Power to Name," 653-55; Adler, Cruising the Library, 1-12; Adler and Tennis, "Taxonomy of Harm," 268-71. 
${ }^{8}$ Olson, "Power to Name," 644-46, 653-55; Olson, Power to Name, 15-16; Adler, Cruising the Library, 1-12; Emily Drabinksi, "Queering the Catalog: Queer Theory and the Politics of Correction," Library Quarterly: Information, Community, Policy 83, no. 2 (2013): 94-105; Vaughan, "Language of Cataloging," 2, 11; Adler and Tennis, "Taxonomy of Harm."

${ }^{9}$ Clare Beghtol, "Professional Values and Ethics in Knowledge Organization and Cataloging," Journal of Information Ethics 17, no. 1 (2008): 13, doi:10.3172/JIE.17.1.12.

${ }^{10}$ Bair, "Toward a Code"; Billie Cotterman, "CaMMS Forum: Power that is Moral: Creating a Cataloging Code of Ethics," ALCTS News, August 19, 2017, https://alcts.ala.org/news/2017/ac-camms-forum/ (accessed July 29, 2020); Jane Daniels, “An International Cataloguing Code of Ethics?,” Catalogue \& Index no. 191 (2018): 20-22.

${ }^{11}$ Cataloging Ethics Steering Committee, "Cataloging Ethics Definition,” Cataloging Ethics Steering Committee, accessed July 29, 2020, https://sites.google.com/view/catalogingethics/home/cataloging-ethics-definition.

${ }^{12}$ IFLA Cataloguing Section, IFLA Meetings of Experts on an International Cataloguing Code, Agnese Galeff, María Violeta Bertolini, Robert L. Bothmann, Elena Escolano Rodríguez, and Dorothy McGarry, Statement of International Cataloguing Principles (ICP) (Den Haag, Netherlands: IFLA, 2017); see also Anna M. Ferris, “The Ethics and Integrity of Cataloging,” Journal of Library Administration 47, no. 3-4 (2008): 173-190, doi:10.1080/01930820802186514.

${ }^{13}$ See, for instance, Daniels, "International Cataloguing Code," 22; Ferris, "Ethics and Integrity," 185.

${ }^{14}$ Bade, Creation and Persistence of Misinformation.

${ }^{15}$ See, for instance, Ferris, "Ethics and Integrity," 180-181.

${ }^{16}$ See, for instance, Olson, "Power to Name;" Steven Joyce, “A Few Gates Redux: An Examination of the Social Responsibilities Debate in the Early 1970s and 1990s," in Questioning Library Neutrality: Essays from Progressive Librarian, ed. Alison Lewis (Duluth, Minnesota: Library Juice Press, 2008), 33-65.

${ }^{17}$ See Adler and Tennis, "Taxonomy of Harm," 266-268; Fox and Reece, "Which Ethics," 378, 382.

${ }^{18}$ See, for instance, Olson, "Power to Name"; Vaughan, "Language of Cataloguing."

${ }^{19}$ Fox and Reece, "Which Ethics," 378.

${ }^{20}$ See, for example, Fox and Reece, "Which Ethics," 379-381; Torbjörn Tännsjö, Understanding Ethics:

An Introduction to Moral Theory, 2nd ed. (Edinburgh: Edinburgh University Press, 2008); John Deigh, An Introduction to Ethics (Cambridge: Cambridge University Press, 2010); Montague

Brown, The Quest for Moral Foundations: An Introduction to Ethics (Washington, D.C.: Georgetown University Press, 1996).

${ }^{21}$ Fox and Reece, "Which Ethics," 377-78. 
${ }^{22}$ Fox and Reece, "Which Ethics," 379; David Banush and Jim LeBlanc, "Utility, Library Priorities, and Cataloging Policies,” accessed July 29, 2020, https://hdl.handle.net/1813/8424; Tännsjö, Understanding Ethics, 17-38; Deigh, Introduction to Ethics, 93-122; Brown, Quest for Moral Foundations, 50-65.

${ }^{23}$ Fox and Reece, "Which Ethics,” 379; Tännsjö, Understanding Ethics, 56-72; Deigh, Introduction to Ethics, 140-56; Brown, Quest for Moral Foundations, 68-86.

${ }^{24}$ Tännsjö, Understanding Ethics, 40-46; Deigh, Introduction to Ethics, 25-55; Brown, Quest for Moral Foundations, 35-42.

${ }^{25}$ Brown, Quest for Moral Foundations, 35-42; Caleb Miller, PHIL 325: Moral Problems (class lecture, Messiah College, Grantham, PA, September 14, 2009).

${ }^{26}$ Fox and Reece, "Which Ethics," 379-80; Brown, Quest for Moral Foundations, 43-48.

${ }^{27}$ Fox and Reece, "Which Ethics," 380; Ray Laura Henry, "Library Technologies and the Ethics of Care," Journal of Academic Librarianship 42, no. 3 (2016): 284-85; Tännsjö, Understanding Ethics, 10916.

${ }^{28}$ Fox and Reece, "Which Ethics," 381; Brown, Quest for Moral Foundations, 124. While Hufford and Hoffman do not explicitly mention this framework in their critique of descriptive cataloging codes (discussed later in the article), their criticisms align with pragmatic ethical concerns; see Jon R. Hufford, "The Pragmatic Basis of Catalog Codes: Has the User Been Ignored?," Cataloging \& Classification Quarterly 14, no. 1 (1991): 27-33; Gretchen L. Hoffman, “Meeting Users' Needs in Cataloging: What is the Right Thing to Do?," Cataloging \& Classification Quarterly 47, no. 7 (2009): 631-41. doi:10.1080/01639370903111999.

${ }^{29}$ Fox and Reece, "Which Ethics," 378.

${ }^{30}$ Ibid., 381-82.

${ }^{31}$ Maurine McCourry, "Domain Analytic, and Domain Analytic-Like, Studies of Catalog Needs:

Addressing the Ethical Dilemma of Catalog Codes Developed with Inadequate Knowledge of User Needs," Knowledge Organization 42, no. 5 (2015): 340.

${ }^{32}$ Information in this paragraph is derived from Lawrence Simpson Guthrie, "Monastic Cataloging and Classification and the Beginnings of 'Class B' at the Library of Congress," Cataloging \& Classification Quarterly 35, no. 3-4 (2003): 447-65. doi:10.1300/J104v35n03_07.

${ }^{33}$ A. Panizzi, "Rules for the Compilation of the Catalogue," in Catalogue of Printed Books in the British Museum (London: The British Museum, 1841), I:v-ix.

${ }^{34}$ This paragraph is summarized from Hufford, "Pragmatic Basis."

${ }^{35}$ Charles A. Cutter, Rules for a Printed Dictionary Catalogue (Washington, DC: Government Printing Office, 1876), 10. 
${ }^{36}$ Charles A. Cutter, Rules for a Dictionary Catalog, 4th ed. (Washington, DC: Government Printing Office, 1904), 6.

${ }^{37}$ See, for example, Frances L. Yocom, A List of Subject Headings for Books by and about the Negro (New York: H. W. Wilson, 1940); Harriet Jackson Scarupa, "The Energy-Charged Life of Dorothy Porter Wesley," New Directions 17, no. 1 (1990): 3.

${ }^{38}$ Brian M. Watson, “'There was Sex but no Sexuality*:' Critical Cataloging and the Classification of Asexuality in LCSH," Cataloging \& Classification Quarterly (2020): 5. doi:10.1080/01639374.2020.1796876.

${ }^{39}$ Sanford Berman, Prejudices and Antipathies: A Tract on the LC Subject Heads Concerning People, 1993 ed. (Jefferson, NC: McFarland, 1993).

${ }^{40}$ In addition to ongoing radical cataloging, a branch referred to as "critical cataloging" formed in the 2000s. See Watson, "There was Sex," 2-3, 5-7.

${ }^{41}$ See Shengang Wang, "The Intellectual Landscape of the Domain of Culture and Ethics in Knowledge Organization: An Analysis of Influential Authors and Works," Cataloging \& Classification Quarterly 57, no. 4 (2019): 232. doi:10.1080/01639374.2019.1614710.

${ }^{42}$ Fina, "Role of Subject Headings"; Henry, "Library Technologies," 284-85; Vaughan, "Language of Cataloging"; and Olson, "Power to Name."

${ }^{43}$ See, for instance, Bair, "Toward a Code of Ethics"; Cotterman, "CaMMS Forum"; Daniels, "International Cataloguing Code"; the "Power that is Moral: Cataloging and Ethics" ALCTS eForum, September 5-6, 2017, starting message: Beth Shoemaker to alcts-eforum@lists.ala.org, September 5, 2017, "Welcome to 'Power that is Moral: Cataloging and Ethics' eForum," https://lists.ala.org/sympa/arc/alcts-eforum/2017-09/msg00000.html (accessed July 30, 2020); and "Ethics of Cataloging," roundtable discussion, Creative Ideas in Technical Services Interest Group Meeting from ALA Annual Conference, Washington, DC, June 22, 2019.

${ }^{44}$ Conference report: Cotterman, "CaMMS Forum".

45 e-Forum summary: Violet Fox and Elizabeth Shoemaker, "Power that is Moral: e-Forum Summary,"

ALCTS News, September 20, 2017, accessed July 29, 2020, https://alcts.ala.org/news/2017/e-forumcataloging-ethics/.

${ }^{46}$ Cataloging Ethics Steering Committee, "Home," Cataloging Ethics Steering Committee, accessed October 28, 2020, https://sites.google.com/view/cataloging-ethics/home.

${ }^{47}$ See, for instance, Bair, "Toward a Code," 13.

${ }^{48}$ Banush and LeBlanc, "Utility, Library Priorities".

${ }^{49}$ This paragraph is summarized from Banush and LeBlanc, "Utility, Library Priorities," 13-18. 
${ }^{50}$ Berman, Prejudices, 15; John Wenzler, "Neutrality and Its Discontents: An Essay on the Ethics of Librarianship," portal: Libraries and the Academy 19, no. 1 (2019): 69-72; David McMenemy, "Librarians and Ethical Neutrality: Revisiting The Creed of a Librarian," Library Review (March 2007).

${ }^{51}$ Robert Jensen, “The Myth of the Neutral Professional," in Questioning Library Neutrality: Essays from Progressive Librarian, ed. Alison Lewis (Duluth, Minnesota: Library Juice Press, 2008), 91; Melissa Adler, "The Case for Taxonomic Reparations," Knowledge Organization 43, no. 8 (2016): 631; S. Macdonald and B. Birdi, "The Concept of Neutrality: A New Approach,” Journal of Documentation 76, no. 1 (2020): 18-21.

${ }^{52}$ Bair, "Toward a Code," 15; Wenzler, "Neutrality and Its Discontents," 58, 63.

${ }^{53}$ Berman, Prejudices, 15.

${ }^{54}$ Wenzler, "Neutrality and Its Discontents," 69; McMenemy, "Librarians and Ethical Neutrality," 3-4;

Gary P. Radford, "Positivism, Foucault, and the Fantasia of the Library: Conceptions of Knowledge and the Modern Library Experience," The Library Quarterly: Information, Community, Policy 62, no. 4 (1992): 412.

${ }^{55}$ Berman, Prejudices, 15-16; Wenzler, "Neutrality and Its Discontents," 69-70; Ferris, "Ethics and Integrity," 180-81.

${ }^{56}$ Macdonald and Birdi, "Concept of Neutrality," 20-21, 25-26; Vaughan, "Language of Cataloging," 1011.

${ }^{57}$ Jensen, "Myth of the Neutral," 91-92; Daniel Martínez Ávila and José Augusto Chaves Guimarães, "Library Classifications Criticisms: Universality, Poststructuralism, and Ethics," Scire (JulyDecember 2013): 22, 25; Drabinski, "Queering the Catalog," 92, 100-05; Vaughan, "Language of Cataloging," 4, 11.

${ }^{58}$ Jensen, "Myth of the Neutral," 92; Vaughan, "Language of Cataloging," 11.

${ }^{59}$ Drabinski, "Queering the Catalog," 92, 100-05; Martínez Ávila and Guimarães, "Library Classifications," 22.

${ }^{60}$ Adler, "Case for Taxonomic Reparations," 61, 65, 68; Vaughan, "Language of Cataloging," 4; Martínez Ávila and Guimarães, "Library Classifications," 23-24.

${ }^{61}$ Vaughan, "Language of Cataloging," 11.

${ }^{62}$ Vaughan, "Language of Cataloging," 10; Olson, "Power to Name," 640; Joyce, “A Few Gates," 54; Jensen, "Myth of the Neutral," 91; Adler, "Case for Taxonomic Reparations," 631.

${ }^{63}$ This entire section is summarized for the most part from discussions on cataloger email lists. See, for example, the following threads: Julie Moore to AUTOCAT@LISTSERV.SYR.EDU, June 7, 2020, “Trigger warnings?," https://listserv.syr.edu/scripts/wa.exe?A2=AUTOCAT;a72f6ee8.2006A 
(accessed July 30, 2020); Emily Thaisrivongs to AUTOCAT @LISTSERV.SYR.EDU, October 4, 2017, "Cataloging a likely hoax,"

https://listserv.syr.edu/scripts/wa.exe?A2=AUTOCAT;cad2335b.1710A (accessed July 30, 2020); J. McRee (Mac) Elrod to AUTOCAT@LISTSERV.SYR.EDU, September 3, 2015, “Re: Hate literature," https://listserv.syr.edu/scripts/wa.exe?A2=AUTOCAT;cdae6151.1509A (accessed July 30, 2020); John G. Marr to AUTOCAT@LISTSERV.SYR.EDU, August 1, 2013, "Re: Objectivity in subject headings," https://listserv.syr.edu/scripts/wa.exe?A2=AUTOCAT;6e8d7f33.1308A (accessed July 30, 2020). See also Beghtol, "Professional Values," 16.

${ }^{64}$ See, for example, IFLA, "Professional Codes of Ethics for Librarians," IFLA, accessed August 27, 2020, https://www.ifla.org/faife/professional-codes-of-ethics-for-librarians (no. 5); ALA, “ALA's Code of Ethics," ALA: American Library Association, accessed August 27, 2020, http://www.ala.org/tools/ethics (no. 7); CILIP, “CILIP's Ethical Framework,” CILIP: The Library and Information Association, accessed August 27, 2020, https://www.cilip.org.uk/page/ethics ("impartiality").

65 “Assigning and Constructing Subject Headings H 180" (Acquisitions and Bibliographic Access Directorate, Washington, DC, 2016), 7, https://www.loc.gov/aba/publications/FreeSHM/H0180.pdf (accessed August 12, 2020).

${ }^{66}$ Also, Sandy Iverson, "Librarianship and Resistance," in Questioning Library Neutrality: Essays from Progressive Librarian, ed. Alison Lewis (Duluth, Minnesota: Library Juice Press, 2008), 33-65; Philip A. Homan, "Library Catalog Notes for 'Bad Books': Ethics Vs. Responsibilities," Knowledge Organization 39, no. 5 (2012): 347-55; Isabel Quintana and Fred J. Hay, “'Calling Out' White Nationalism in Our Catalogs: Some Suggestions" (session presented at the $96^{\text {th }}$ Annual PTPL Meeting, October 16, 2020).

${ }^{67}$ Example suggested by one of the article's anonymous peer reviewers.

${ }^{68}$ See, for example, Brian Briscoe to AUTOCAT@LISTSERV.SYR.EDU, December 9, 2015, "Re: Whoa! Sherlock refictionalized - was Re: Change in policy on (Fictitious character) qualifier?," https://listserv.syr.edu/scripts/wa.exe?A2=AUTOCAT;68daf9c0.1512B (accessed November 9, 2020).

${ }^{69}$ See Thaisrivongs to AUTOCAT@LISTSERV.SYR.EDU, “Cataloging a likely hoax.”

${ }^{70}$ See Homan, "Library Catalog Notes," 347-55.

${ }^{71}$ See Quintana and Hay, “'Calling Out' White Nationalism.”

${ }^{72}$ Fina, "Role of Subject Headings"; Vaughan, "Language of Cataloging"; Fox and Reece, "Which Ethics," 377; Mackenzie Johnson and Carlie Forsythe, "Disability and Accessibility Language in Subject Headings and Social Tags," Catalogue and Index 197 (December 2019): 16-26; Ann M. 
Doyle, Kimberley Lawson, and Sarah Dupont, "Indigenization of Knowledge Organization at the X $w$ i7 $x w a$ Library," Journal of Library and Information Studies 13, no. 2 (2015): 111-12.

${ }^{73}$ For example, "Women scientists" and "African American scientists" are headings, but "Men scientists" (or "Male scientists") and "Caucasian American scientists" (or "White scientists") are not. Likewise, "Male contraception" is a heading, but not "Female contraception." See Olson, Power to Name, 153-59; Ferris, "Ethics and Integrity," 182; Vaughan, "Language of Cataloging," 11; Olson, "Power to Name," 646-47.

${ }^{74}$ Olson, "Power to Name," 656-58; Doyle, Lawson, and Dupont, "Indigenization of Knowledge Organization," 111-12, 122; Olson, Power to Name, 163-64; Vaughan, "Language of Cataloging," 12. For instance, Vaughan points out that only a fraction of the approximately 4,000-5,000 Indigenous people groups living in the world have a specific heading; works on the rest are expected to be given the general heading "Indigenous peoples" as though all such cultures are interchangeable.

${ }^{75}$ See Fina, "Role of Subject Headings," 270-71; Drabinski, "Queering the Catalog"; Vaughan, "Language of Cataloging"; Adler and Tennis, "Taxonomy of Harm"; Bair, "Toward a Code," 10-11; Johnson and Forsythe, "Disability and Accessibility Language"; Doyle, Lawson, and Dupont, "Indigenization of Knowledge Organization," 111-12.

${ }^{76}$ See Fina, "Role of Subject Headings," 270-71; Drabinski, "Queering the Catalog"; Vaughan,

"Language of Cataloging"; Adler and Tennis, "Taxonomy of Harm"; Bair, "Toward a Code," 10-11.

${ }^{77}$ Olson, "Power to Name," 646-47; Bair, "Towards a Code," 10-11.

${ }^{78}$ Adler, Cruising the Library, 8.

${ }^{79}$ Vaughan, "Language of Cataloging," 8, 11; Olson, "Power to Name," 659-61.

${ }^{80} \mathrm{See}$, for instance, Christine Bone and Brett Lougheed, "Library of Congress Subject Headings Related to Indigenous Peoples: Changing LCSH for use in a Canadian Archival Context," Cataloging \& Classification Quarterly 56, no. 1 (2018): 83-95; Marisa Elena Duarte and Miranda Belarde-Lewis, "Imagining: Creating Spaces for Indigenous Ontologies," Cataloging \& Classification Quarterly 53, no. 5-6 (2015): 677-702. doi:10.1080/01639374.2015.1018396; Doyle, Lawson, and Dupont, "Indigenization of Knowledge Organization," 112-13, 116-17; Adler, "Case for Taxonomic Reparations;" Vaughan, "Language of Cataloging," 12.

${ }^{81}$ Information about the history of "Illegal alien" is summarized from Vaughan, "Language of Cataloging," 5-7; and SAC Working Group on Alternatives to LCSH "Illegal aliens," "Report of the SAC Working Group on Alternatives to LCSH 'Illegal aliens"” (ALA/ALCTS/CaMMS Subject Analysis Committee, 2020), 1-3, http://hdl.handle.net/11213/14582 (accessed July 30, 2020). ${ }^{82}$ SAC Working Group on Alternatives to LCSH "Illegal aliens," "Report," 3. 
${ }^{83}$ Vaughan, "Language of Cataloging," 6-7.

${ }^{84}$ SAC Working Group on the LCSH "Illegal aliens," "Report from the SAC Working Group on the

LCSH 'Illegal aliens'” (ALA/ALCTS/CaMMS Subject Analysis Committee, 2016),

http://hdl.handle.net/11213/9261 (accessed July 30, 2020).

${ }^{85}$ SAC Working Group on Alternatives to LCSH "Illegal aliens," "Report," 5.

${ }^{86}$ Fina, "Role of Subject Headings," 269-70.

${ }^{87}$ Ibid.

${ }^{88}$ Adler, Cruising the Library, 26; Olson, "Power to Name," 653.

${ }^{89}$ Martínez Ávila and Guimarães, "Library Classifications," 24; Vaughan, "Language of Cataloging," 3; Drabinski, "Queering the Catalog," 95; Doyle, Lawson, and Dupont, "Indigenization of Knowledge Organization," 111-12; Adler and Tennis, “Taxonomy of Harm,” 270; Olson, Power to Name, 12.

${ }^{90}$ Adler, Cruising the Library, 15-17; Violet Fox, "Why Are the 200s so Heavily Focused on Christianity? An Explainer," 025.431: The Dewey blog, November 7, 2019, https://ddc.typepad.com/025431/2019/11/why-are-the-200s-so-heavily-focused-on-christianity-anexplainer.html (accessed August 14, 2020); Sara A. Howard and Steven A. Knowlton, "Browsing through Bias: The Library of Congress Classification and Subject Headings for African American Studies and LGBTQIA Studies," Library Trends 67, no. 1 (2018): 74.

${ }^{91}$ See Berman, Prejudices, 15-16; Fox, "Why Are the 200s;"Adler, "Case for Taxonomic Reparations," 63; Olson, Power to Name, 29, 114; Vaughan, "Language of Cataloging," 10; Ferris, "Ethics and Integrity," 182.

92 Doyle, Lawson, and Dupont, "Indigenization of Knowledge Organization," 111-12; Catelynne Sahadath, "Classifying the Margins: Using Alternative Classification Schemes to Empower Diverse and Marginalized Users," Feliciter 59, no. 3 (2013): 15-17; Adler, "Case for Taxomonic Reparations," 62; Vaughan, "Language of Cataloging," 8-9.

${ }^{93}$ Drabinski, "Queering the Catalog," 97; Sahadath, "Classifying the Margins," 15; Fox, "Why are the 200s."

${ }^{94}$ Howard and Knowlton, "Browsing through Bias," 75-77; see also Olson, "Power to Name," 654-55; Olson, Power to Name, 175.

${ }^{95}$ Sahadath, "Classifying the Margins," 16; Doyle, Lawson, and Dupont, "Indigenization of Knowledge Organization," 112-13, 117-20.

${ }^{96}$ Drabinski, "Queering the Catalog," 95-97, 101; Vaughan, "Language of Cataloging," 3.

${ }^{97}$ Drabinski, "Queering the Catalog," 101-108.

${ }^{98}$ Vaughan, "Language of Cataloging," 2, 5, 10-12. 
${ }^{99}$ This premise is also applied to terms in subject headings and classification lists. See Sahadath, "Classifying the Margins," 16.

${ }^{100}$ Amber Billey, Emily Drabinski, and K. R. Roberto, "What's Gender Got to Do with It? A Critique of RDA 9.7," University Libraries Faculty and Staff Publications 19 (2014): 7, https://scholarworks.uvm.edu/libfacpub/19 (accessed June 17, 2020).

${ }^{101}$ Ibid., 3-4.

${ }^{102}$ Ibid., 1-14.

${ }^{103}$ Ibid., 12. Ethnicity was excluded because it was deemed to be too complicated for a cataloger to determine accurately.

${ }^{104}$ Amber Billey, Matthew Haugen, John Hostage, Nancy Sack, and Adam L. Schiff, "Report of the PCC Ad Hoc Task Group on Gender in Name Authority Records" (Program for Cooperative Cataloging, 2016), https://www.loc.gov/aba/pcc/documents/Gender_375\%20field_RecommendationReport.pdf (accessed July 30, 2020).

${ }^{105}$ See "Part III: Gender Variance and Transgender Identities," in Ethical Questions in Name Authority Control, ed. Jane Sandberg (Sacramento, CA: Library Juice Press, 2019), 111-211; Travis L.

Wagner, "Transcribe as Seen: Challenging RDA regarding Gender in Moving Image Materials," in Organization, Representation, and Description through the Digital Age: Information in Libraries, Archives, and Museums, ed. Christine M. Angel and Caroline Fuchs (Berlin, Germany: De Gruyter, 2018), 177-188.

106 Tom Delsey, “Authority Control in an International Context," Cataloging \& Classification Quarterly 9, no. 3 (1989): 16.

${ }^{107}$ Sanford Berman, "When the Subject is Indians," American Indian Libraries Newsletter 18, no. 2 (1995); Erin Elzi and Katherine M Crowe, “This is the Oppressor's Language Yet I Need It to Talk to You: Native American Name Authorities at the University of Denver," in Ethical Questions in Name Authority Control, ed. Jane Sandberg (Sacramento, CA: Library Juice Press, 2019), 71-98; Heather K. Hughes, "Cataloging Kurdistan: Imagining Liberated Geographies," in Ethical Questions in Name Authority Control, ed. Jane Sandberg (Sacramento, CA: Library Juice Press, 2019), 99-107; Jack Maness, Shannon Tharp, and Denisse Solis, "New Research in Collection Management," lecture, ALCTS Collection Management Section program from the ALA Annual Conference, Washington, DC, June 22, 2019 (conference report: Jennifer Martin, "New Research in Collection Management," ALCTS News (August 2, 2019), https://alcts.ala.org/news/2019/new-research-incollection-management-alaac19/ (accessed July 30, 2020)).

${ }^{108}$ Bair, "Towards a Code," 12. 
${ }^{109}$ See, for instance, Maness, Tharp, and Solis, "New Research in Collection Management"; Bone and Lougheed, "Library of Congress Subject Headings."

${ }^{110}$ Gorman, Michael, A Study of the Rules for Entry and Heading in the Anglo-American Cataloguing Rules, 1967 (London: Library Association, 1968), 66-67.

${ }^{111}$ Hufford, "Pragmatic Basis."

${ }^{112}$ Hoffman, "Meeting Users' Needs."

${ }^{113}$ See, for example, McCourry, "Domain Analytic," 344; and email list threads: Hal Cain to AUTOCAT@LISTSERV.SYR.EDU, April 15, 2014, “Re: Advantages of RDA,” https://listserv.syr.edu/scripts/wa.exe?A2=AUTOCAT;7fd9b80d.1404C (accessed July 30, 2020); Bonnie Powers to AUTOCAT@LISTSERV.SYR.EDU, January 14, 2013, “Why should RDA matter to me?," https://listserv.syr.edu/scripts/wa.exe?A2=AUTOCAT;fab05ded.1301B (accessed July 30, 2020); Kevin M. Randall to AUTOCAT@LISTSERV.SYR.EDU, July 18, 2012, “Lack(?) of research, or, Let's hear it for the nobodies," https://listserv.syr.edu/scripts/wa.exe?A2=AUTOCAT;e6e48cf9.1207C (accessed July 30, 2020).

${ }^{114}$ Gorman, Study of the Rules, 66-67.

${ }^{115}$ Hufford, "Pragmatic Basis."

${ }^{116}$ Hoffman, "Meeting Users' Needs."

${ }^{117}$ Hoffman, "Meeting Users' Needs," 633-34; Hufford, "Pragmatic Basis,” 27; and McCourry, "Domain Analytic," 339-40.

${ }^{118}$ Hoffman, "Meeting Users' Needs,” 367-68; Hufford, "Pragmatic Basis," 31-32; and McCourry, "Domain Analytic," 339-40, 344.

${ }^{119}$ See, for example, this email thread: Aaron Kuperman to AUTOCAT@LISTSERV.SYR.EDU, September 22, 2008, "Re: COST OF RDA???," https://listserv.syr.edu/scripts/wa.exe?A2=AUTOCAT;dc3911e7.0809D (accessed August 14, 2020).

${ }^{120}$ Bair, "Toward a Code," 8, 13-14; "Ethics of Cataloging” roundtable.

121 Thread: Janet Schrader to OCLC-CAT@OCLC.ORG, March 24, 2011, "What's allowed in 520 fields now?," http://listserv.oclclists.org/scripts/wa.exe?A2=OCLC-CAT;5eede8a8.1103D (accessed July 30, 2020); "Ethics of Cataloging" roundtable.

${ }^{122}$ Henry, "Library Technologies." 